\title{
Reciprocal Effects of Silicon Supply and Endophytes on Silicon Accumulation and Epichloë Colonization in Grasses
}

\section{OPEN ACCESS}

Edited by:

Pedro Emilio Gundel, University of Buenos Aires, Argentina

Reviewed by:

Chunjie Li,

Lanzhou University, China Kari Saikkonen, University of Turku, Finland Benjamin Fuchs,

University of Turku, Finland

*Correspondence:

Ximena Cibils-Stewart xcibils@inia.org.uy

Specialty section: This article was submitted to Plant Symbiotic Interactions, a section of the journal

Frontiers in Plant Science

Received: 10 August 2020 Accepted: 07 October 2020 Published: 27 October 2020

Citation:

Cibils-Stewart X, Powell JR, Popay AJ, Lattanzi FA, Hartley SE and Johnson SN (2020) Reciprocal Effects of Silicon Supply and Endophytes on Silicon Accumulation and Epichloë

Colonization in Grasses.

Front. Plant Sci. 11:593198. doi: 10.3389/fp/s.2020.593198

\author{
Ximena Cibils-Stewart ${ }^{1,2 *}$, Jeff R. Powell ${ }^{1}$, Alison Jean Popay ${ }^{3}$, \\ Fernando Alfredo Lattanzi ${ }^{2}$, Sue Elaine Hartley ${ }^{4}$ and Scott Nicholas Johnson ${ }^{1}$ \\ ${ }^{1}$ Hawkesbury Institute for the Environment, Western Sydney University, Penrith, NSW, Australia, ${ }^{2}$ Instituto Nacional \\ de Investigación Agropecuaria, Colonia, Uruguay, ${ }^{3}$ AgResearch, Ruakura Research Centre, Hamilton, New Zealand, \\ ${ }^{4}$ Department of Animal and Plant Sciences, The University of Sheffield, Sheffield, United Kingdom
}

Cool season grasses associate asymptomatically with foliar Epichloë endophytic fungi in a symbiosis where Epichloë spp. protects the plant from a number of biotic and abiotic stresses. Furthermore, many grass species can accumulate large quantities of silicon (Si), which also alleviates a similar range of stresses. While Epichloë endophytes may improve uptake of minerals and nutrients, their impact on Si is largely unknown. Likewise, the effect of Si availability on Epichloë colonization remains untested. To assess the bidirectional relationship, we grew tall fescue (Festuca arundinacea) and perennial ryegrass (Lolium perenne) hydroponically with or without Si. Grasses were associated with five different Epichloë endophyte strains [tall fescue: AR584 or wild type (WT); perennial ryegrass: AR37, AR1, or WT] or as Epichloë-free controls. Reciprocally beneficial effects were observed for tall fescue associations. Specifically, Epichloë presence increased $\mathrm{Si}$ concentration in the foliage of tall fescue by at least 31\%, regardless of endophyte strain. In perennial ryegrass, an increase in foliar Si was observed only for plants associated with the AR37. Epichloë promotion of Si was (i) independent of responses in plant growth, and (ii) positively correlated with endophyte colonization, which lends support to an endophyte effect independent of their impacts on root growth. Moreover, Epichloë colonization in tall fescue increased by more than $60 \%$ in the presence of silicon; however, this was not observed in perennial ryegrass. The reciprocal benefits of Epichloë-endophytes and foliar Si accumulation reported here, especially for tall fescue, might further increase grass tolerance to stress.

Keywords: silica, Epichloë, hydroponics, perennial ryegrass (Lolium perenne L.), tall fescue (Festuca arundinacea S.)

\section{INTRODUCTION}

Symbiotic relationships between plants and fungi have a long evolutionary history with plant fossils containing fungal endophytes dating back 400-million-years (Krings et al., 2007). Worldwide, many cool-season $\left(\mathrm{C}_{3}\right)$ grasses, including important wild and domesticated species, associate asymptomatically with Epichloë fungi (Ascomycota: Clavicipitaceae) (Leuchtmann, 1992; Kauppinen et al., 2016). Asexual Epichloë endophytes reside intercellularly (apoplastic space) in 
aerial plant parts, and are vertically transmitted via host seed (Leuchtmann, 1992; Christensen et al., 2008). Epichloë endophytes are true obligate symbionts, and their growth is tightly synchronized with their host plant (Christensen et al., 2008). Epichloë-grass associations are known to benefit grasses in a number of ways, including increased growth (Gundel et al., 2013), better tolerance to water deficits (Rho et al., 2018) and resistance to pathogens (Xia et al., 2018) and herbivores (Bastias et al., 2017), the latter mainly via production of endophyte specific protective alkaloids (nitrogenous compounds) (Bastias et al., 2017). While some studies suggest endophytes play a limited role in stress alleviation (Niones and Takemoto, 2014; Wiewióra et al., 2015; Heineck et al., 2020), and might have antagonistic responses under extreme resource limitations conditions (Cheplick et al., 1989; Cheplick, 2007; Saikkonen et al., 2016), it is recognized that their beneficial effects are now widely reported (Kuldau and Bacon, 2008; Perez et al., 2017). Because of these benefits, animal-safe endophytes strains (e.g., AR1, AR31, AR584), that don't have the genes accountable for producing mammalian toxic alkaloids, are commercially available in marketed varieties of several perennial forage grasses such as tall fescue, perennial ryegrass, and cocksfoot (Gundel et al., 2013; Kauppinen et al., 2016). These animal-safe strains improve forage quality and persistence, and maintain endophytemediated resistance to insects pests without affecting grazing mammals (Gundel et al., 2013); some negative repercussions have been reported for horses, however (Munday et al., 2017).

Additionally, it is long known that grasses are high accumulators of silicon ( $\mathrm{Si}$ ) (Raven, 1983), especially perennial species that co-evolved with herbivores (Massey et al., 2007; Cooke and Leishman, 2011). Si can account for up to $10 \%$ of dry mass, and grasses take up more Si than any other inorganic constituent (Epstein, 1994; Kumar et al., 2017). Silicon is taken up by the roots as monosilicic acid $\left(\mathrm{H}_{4} \mathrm{SiO}_{4}\right)$, using either passive (transpiration flow) or active (membrane transporters) mechanisms, before polymerizing in cell walls (Ma and Yamaji, 2015; Coskun et al., 2019). Plant silicification (anamorphous Si deposits) occurs in cell walls, cell lumens, intercellularly (apoplastic space), or within leaf surfaces (e.g., trichomes or phytoliths) (Kumar et al., 2017). Once polymerized, Si cannot be remobilized (Hartley et al., 2015). Silicification of plant tissues has been shown to alleviate a wide range of stresses, some of which are similarly alleviated by Epichloë endophyte associations. Stresses alleviated by Si include herbivory (Hartley et al., 2015; Reynolds et al., 2016), pathogens (Vivancos et al., 2015; Rasoolizadeh et al., 2018), low temperatures (Zhang et al., 2008), UV radiation (Tripathi et al., 2017), and nutrient deficiency (Miao et al., 2010). The mechanisms underpinning this stress alleviation remain controversial but silicification of plant tissues may provide physical resistance (Coskun et al., 2019) or indirectly cause changes in plant chemistry (Hall et al., 2019). Moreover, Si supplementation has also been reported to increase plant growth (Frew et al., 2018) and enhance uptake of major essential nutrients (Eneji et al., 2008), although these effects mostly take place during stressful conditions (Coskun et al., 2019). For these reasons, Si is promoted as a sustainable fertilizer (Eneji et al., 2008).
Despite endophytes and $\mathrm{Si}$ accumulation being important for many grass species, and given that they perform similar functions, their effects have mostly been studied separately. Thus, it is currently unknown if and how Epichloë endophytes and Si interact (Johnson et al., 2016). To date, only one field study noted that meadow fescue (Festuca pratensis) colonized with Epichloë uncinata contained 16\% more Si relative to non-symbiotic plants (Huitu et al., 2014). Although this field study did not control for Si-availability, it provides indirect evidence that that endophytes might increase $\mathrm{Si}$ concentrations in grasses.

Several putative mechanisms could be envisaged for endophytes and $\mathrm{Si}$ impacting one another. For instance, both endophyte (Christensen et al., 2008) and Si (Kumar et al., 2017) can occupy the same apoplastic (intercellular) space in leaves. Therefore, Si deposition could reduce spatial niches for Epichloë-mycelium, thereby hindering colonization. Additionally, both endophyte (Cheplick and Faeth, 2009) and Si (Ma and Yamaji, 2015) acquisition come at a metabolic cost to the plant, thus, there may be an optimal balance between $\mathrm{Si}$ accumulation and endophyte colonization. Finally, although Epichloë colonize aboveground plant tissues, they are known to influence several belowground plant functions, including nutrient/mineral acquisition, thus, may increase Si uptake. These effects are rather indirect, mediated by changes in plant growth. For instance, Epichloë can increase leaf area and transpiration rate, and thus nutrient acquisition via mass flow (Malinowski and Belesky, 2000; Soto-Barajas et al., 2016; Llorens et al., 2019), can promote changes in root growth and architecture (e.g., increasing length, reduced diameter, and longer hairs) that increase nutrient concentration gradients (Malinowski and Belesky, 2000; Ren et al., 2007; García Parisi et al., 2015) or facilitate interception with nutrient pools in the soil (Malinowski et al., 1998, 2004; Malinowski and Belesky, 2000; Ren et al., 2007; Soto-Barajas et al., 2016). Endophytes might affect soil organisms that actively facilitate nutrient absorption processes (e.g., arbuscular mycorrhizae fungi) (Novas et al., 2011). Likewise, endophyte can increase root exudation of phenolic compounds that acidify the rhizosphere and improve mineral uptake (Malinowski et al., 1998, 2004).

The objective of this study was to determine whether Si interacts with different Epichloë endophytes strains in the two most used perennial pasture grasses worldwide; tall fescue and perennial ryegrass. Specifically, five different Epichloë strains were utilized, three animal-safe strains, AR584 in tall fescue, and AR1/AR37 in perennial ryegrass, as well as their wild type (WT) (mammalian toxic) counterparts for both grasses; along with Epichloë-free controls. Both extensively used commercial animal-safe (novel) and WT strains were utilized to determine if strain-specific effects occur. In particular, we addressed three specific research questions:

(i) Do Epichloë-endophytes increase Si concentrations in foliage?

(ii) Is endophyte-mediated variation in $\mathrm{Si}$ concentration dependent of symbiosis induced changes in plant growth?

(iii) Does Si supplementation affect endophyte colonization? 


\section{MATERIALS AND METHODS}

\section{Experimental Procedure}

Seeds of tall fescue (Festuca arundinacea) cv. INIA Fortuna and perennial ryegrass (Lolium perenne) cv. Samson were obtained from the Margot Forde Germplasm Centre (Palmerston North, New Zealand). Epichloë strains utilized were the novel AR584 and the common-toxic (WT) in tall fescue, and the novel AR1 and AR37, and the commontoxic (WT) for perennial ryegrass, along with Epichloë-free controls (Nil) (Hume et al., 2013) (see section "Epichloë Detection and Mycelium Mass"). These germplasm was utilized to evaluate the effect of endophyte on foliar silicon concentrations.

All seeds were surface sterilized and transferred to trays with wet perlite growing media in a naturally lit glasshouse under controlled environmental conditions of $22 / 18^{\circ} \mathrm{C}$ (day/night), $50 \%$ relative humidity, at the Hawkesbury Institute for the Environment, Richmond, NSW, Australia. Eleven-days after germination, uniformly sized individual seedlings were transferred to polypropylene 50-mL LightSafe tubes (Sigma-Aldrich, St. Louis, MO, United States) containing $45-\mathrm{mL}$ of nutrient solution with $(+\mathrm{Si})$ or without $(-\mathrm{Si})$ silicon $(\mathrm{Si})$, as described in Hall et al. (2020) adapted from Jung et al. (2015) and Hall et al. (2020).

The solution contained: $1 \mathrm{mM} \mathrm{KNO}_{3}, 1 \mathrm{mM} \mathrm{Ca}\left(\mathrm{NO}_{3}\right)_{2}$, $1 \mathrm{mM} \mathrm{KH} \mathrm{KO}_{4}, 0.6 \mathrm{mM} \mathrm{MgSO}, 100 \mu \mathrm{M} \mathrm{NaCl}, 15 \mu \mathrm{M}$ $\mathrm{H}_{3} \mathrm{BO}_{3}, 0.5 \mu \mathrm{M} \mathrm{MnCl}, 0.7 \mu \mathrm{M} \mathrm{ZnSO}_{4}, 0.8 \mu \mathrm{M} \mathrm{Na} \mathrm{MoO}_{4}$, $0.8 \mu \mathrm{M} \mathrm{CuSO}, 100 \mu \mathrm{M}$ NaFe EDTA (Sigma Aldrich, St. Louis, MO, United States). To generate + Si treatments, liquid potassium silicate was added to the nutrient solution $\left(\mathrm{K}_{2} \mathrm{SiO}_{3}\right.$; Agsil32, PQ Australia, SA, Australia) at a concentration equivalent to $2 \mathrm{mM} \mathrm{SiO}_{2}$. Chemically, silicic acid polymerizes to form silica gel $\left(\mathrm{SiO}_{2} \mathrm{nH}_{2} \mathrm{O}\right)$ when the concentration of silicic acid exceeds $2 \mathrm{mM}$ (Ma and Yamaji, 2006). To balance the additional potassium $(\mathrm{K})$ and chloride $(\mathrm{Cl})$ ions in the $+\mathrm{Si}$ treatments, potassium chloride $(\mathrm{KCl})$ was added to the control nutrient solution $(-\mathrm{Si})$. Lastly, the $\mathrm{pH}$ of both solutions $(+\mathrm{Si} /-\mathrm{Si})$ was adjusted to 5.6-6 using hydrochloric acid $(2 \mathrm{M} \mathrm{HCl})$ to reduce the polymerization of silicates (Ma and Yamaji, 2006).

The combination of grass species, endophyte strain and Si supply resulted in 14 treatments performed in two experimental stages. Experimental stages were deployed 4 weeks apart with at least 10 replicates of each treatment (183 plants in total; see Supplementary Table S1 for initial and final replication). The first stage was limited to tall fescue either infected with AR584 or not (Nil) and supplied with $(+\mathrm{Si})$ or without $\mathrm{Si}(-\mathrm{Si})$, resulting in four treatments. The second stage included all Epichlö by genotype combinations tested in a factorial combination with and without Si.

Plants were grown in their corresponding Si treatment for a further 7 week period to ensure functional Epichloë-grass symbiosis (Hume et al., 2013; Kaur et al., 2015). Tubes within the glasshouse were shifted randomly every week to minimize position bias, and the nutrient solution was refreshed three times a week to ensure optimal growth conditions.

At each harvest (Supplementary Figure S1) two of the thickest tillers of each plant were blotted for Epichloë detection (see section "Epichloë Detection and Mycelium Mass"). Individual shoots and roots were separated, ovendried at $60^{\circ} \mathrm{C}$, weighed (MS-TA Analytical balances; Mettler Toledo) and milled.

\section{Epichloë Detection and Mycelium Mass}

Before initiating experiments, 100 mature seeds from each germplasm were stained with aniline blue and examined under the microscope $(40 \times)$ to corroborate presence or absence (Nil) of endophyte hyphae in the aleurone cells (Latch and Christensen, 1985). Histological detection confirmed infection rates higher than $95 \%$ in infected seeds, and less than 3\% infection in Nil. However, seed detection does not test endophyte viability.

Consequently, Epichloë viability in planta, a measure of vegetative colonization efficacy, was performed in all 183 experimental plants using tissue-print immunoblotting and histological detection immediately after harvest (Hahn et al., 2003). For tissue-print immunoblotting, the fresh cut end of each tiller was pressed onto a nitrocellulose membrane (Hahn et al., 2003; di Menna et al., 2012). Tissue-print immunoblotting results were further confirmed through histological staining (aniline blue), whereby a section of the epidermal strips from the outermost leaf sheath of $20 \%$ of the plants in each Epichloë germplasm combination $(n=7)$ were examined under a light microscope to corroborate presence or absence (Nil) of endophyte hyphae in intercellular spaces (di Menna et al., 2012). Immunoblotting results and histological tissue staining coincided for the subset of plants evaluated. A total of 17 plants had the wrong endophyte status (e.g., Nil that were positive) and were removed from all analyses (final replication provided in Supplementary Table $\mathbf{S 1}$ and in Figures 1, 2, 4).

Epichloë-mycelial mass was further quantified in at least five replicates per treatment (Supplementary Table S2) using sandwich ELISA following Easton et al. (2002) procedures, modified from Miles et al. (1998). Epichlö̈-mycelial mass was used as a measure of tissue-colonization (Easton et al., 2002). Briefly, approximately $20 \mathrm{mg}$ of milled shoot tissue per plant were utilized. Samples were extracted utilizing $10 \mathrm{~mL}$ of phosphate buffered saline with Tween (1\%), inverted to mix, incubated with the anti-endophyte antibody for $3 \mathrm{~h}$ at $37^{\circ} \mathrm{C}$, and stored in the fridge overnight $\left(4^{\circ} \mathrm{C}\right)$. An aliquot of $150 \mu \mathrm{L}$ was taken for the ELISA. ELISA standard curves were prepared for each assay using Neotyphodium lolii (now E. festucae var. lolii) as standards (Miles et al., 1998; Easton et al., 2002). To minimize the effects of interplate variation, each grass sample was analyzed twice. $\mathrm{A}_{405}$ was measured with a Bio-Rad model 3550 microplate reader. The plates were washed three times with PBS after the antibodycoating and -blocking steps and twice with PBS-Tween (0.05\%) and once with PBS after the sample and conjugate incubation steps (Miles et al., 1998; Easton et al., 2002). Undetectable levels of mycelium following sandwich ELISA confirmed absence of endophyte in all Nil plants. 


\section{A Tall fescue}

ENDO $F_{2,44}=5.44, P=0.007$

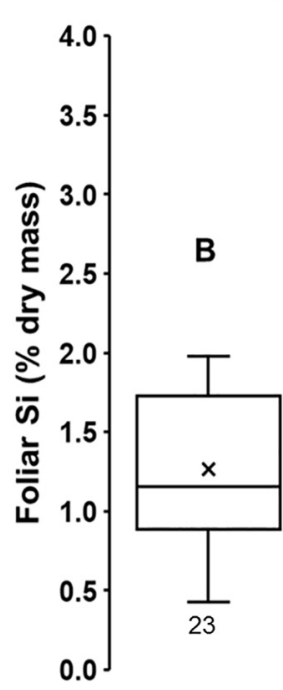

Endophytes

口Nil पWT

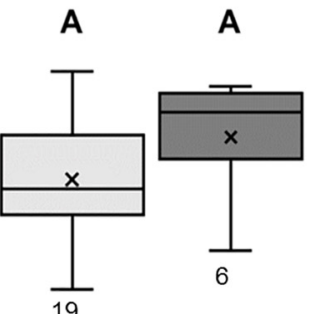

A
B Perennial ryegrass

ENDO $F_{3,31}=8.47, P<0.001$ 口AR584

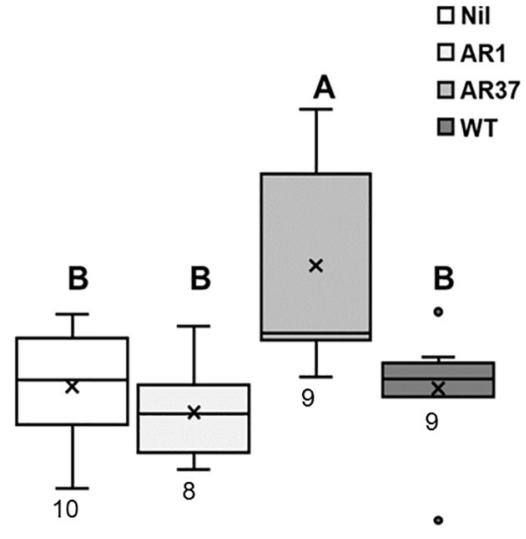

FIGURE 1 | Foliar Si concentration of (A) tall fescue and (B) perennial ryegrass plants without endophytes (Nil) or colonized with different Epichloë endophyte strains growing hydroponically in the presence of silicon (Si). Mean values indicated with ' $X$ ' and lines depict inclusive median and interquartile range; resulting $\mathrm{N}$ indicated below each box plot (see Supplementary Table S1). Different letters indicate significant differences $(P<0.05)$.

\section{Foliar Si}

Foliar Si concentration was measured on all replicates (166 plants) on $\sim 80-100 \mathrm{mg}$ of ground shoot tissue using X-ray fluorescence spectrometry (Epsilon 3x; PANalytical, EA Almelo, Netherlands), following Reidinger et al. (2012) procedures.

Specifically, milled samples were placed individually inside small-mass holders (PANalytical, B.V., Netherlands), and Si concentrations were measured in the presence of helium (Hiltpold et al., 2016). Si was expressed as \% of dry mass, and samples were calibrated against a certified control (NCS ZC73018, Citrus leaves, China National Institute for Iron and Steel) (Hiltpold et al., 2016). - Si treatment was verified, given that all $-\mathrm{Si}$ plants contained undetectable levels of $\mathrm{Si}$ (Hiltpold et al., 2016).

\section{Statistical Analysis}

R (version 4.0.0; R Core Team, 2020) was utilized for all statistical analyses. Sample sizes were unbalanced due to removal of plants with wrong Epichloë status (Supplementary Table S1). Assumptions of normality for residuals were verified according to inspection of quantile-quantile plots. Moreover, since the experiment was performed in two time-lapsed stages, experimental 'stage' was accounted as a random effect in all models (Supplementary Table S1).

Root, shoot, and total biomass were analyzed with a twoway ANOVA with endophyte and Si status, and their interaction included as factors for each grass species in separate models. Biomass traits were additionally analyzed using a one-way ANOVA for each endophyte strain individually with Si status as a factor. Since endophytes increased root growth (see below), we tested the independent effects of endophytes on foliar $\mathrm{Si}$ concentration using a one-way ANCOVA, with endophyte status as a fixed factor and root mass fitted as a covariate. Additionally, a Spearman's rank correlation coefficient test using the 'cor.test' function in $\mathrm{R}$ was commuted to analyze the relationship between foliar Si concentrations and Epichloë colonization for each Epichloë-strain separately. Lastly, colonization of each Epichloëstrain was analyzed with a one-way ANOVA using Si treatment as a predictor to determine the effects of Si on endophyte mycelium mass (proxy for colonization).

\section{RESULTS}

Results showed evidence of strong interaction between Epichloë endophyte and Si. The presence of Epichloë consistently increased foliar Si concentrations in tall fescue plants with increases of 31\% in plants associated with AR584 and 52\% in plants associated with WT endophyte, relative to Epichloë-free (Nil) plants (Figure 1A). In perennial ryegrass, foliar $\mathrm{Si}$ concentrations increased by $47 \%$ only in plants associated with AR37 endophyte (Figure 1B); while the other plants displayed similar concentrations to those of Nil plants (Figure 1B).

Neither endophytes nor the addition of $\mathrm{Si}$ influenced shoot biomass for either grass species. Root biomass, however, was significantly increased by endophytes in both species (Figure 2 and Table 1). Including root dry mass as a covariate in ANCOVA indicated that the increased root mass associated with endophyte presence did not fully explain observed increases in foliar $\mathrm{Si}$ concentrations in either grass species; tall fescue $\left(F_{1,44}=1.55\right.$, 


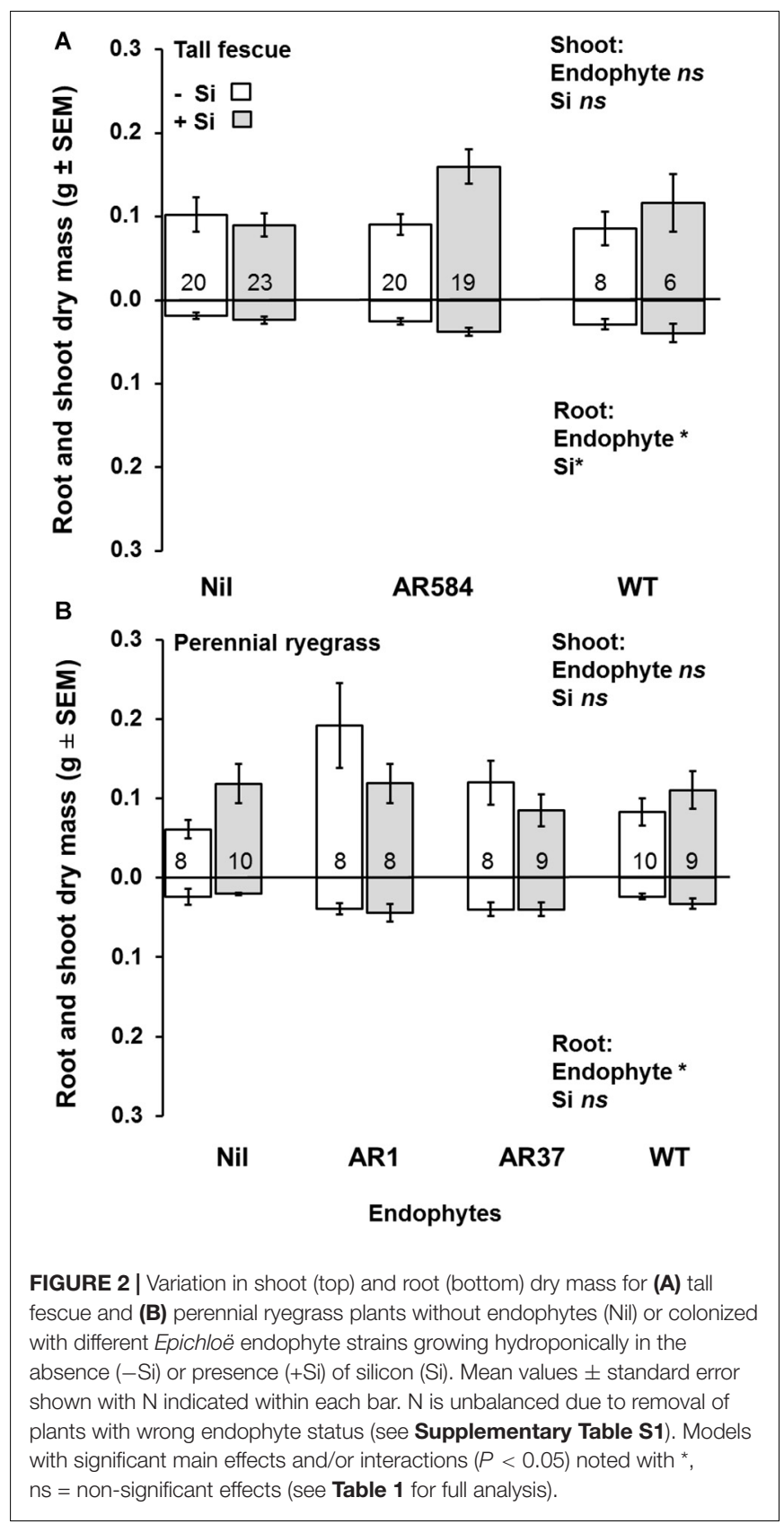

$P=0.22)$ nor perennial ryegrass $\left(F_{1,31}=1.63, P=0.21\right)$. In short, foliar $\mathrm{Si}$ concentrations were higher in endophyte colonized plants irrespective of the increased root mass observed in these plants. When traits were analyzed for each endophyte strain separately, Si significantly increased shoot, root, and total biomass only for AR584-symbiotic tall fescue (Table 2). Other than for AR584, Si did not impact growth traits of the other strains tested in either tall fescue or in perennial ryegrass (Table 2).

Whenever endophyte effects on foliar Si concentration were observed, positive relationships between Epichloë mycelial mass and foliar Si concentrations were also detected in both tall fescue (i.e., AR584 and WT strains; Figure 3A) and perennial ryegrass (i.e., AR37 strain; Figure 3B).

Lastly, there was a significant effect of Si supply on endophyte colonization in tall fescue, but not for perennial ryegrass. Specifically, tall fescue plants in the $+\mathrm{Si}$ treatment had 80 and $60 \%$ higher mycelial masses than their Nil counterparts for $\operatorname{AR584}\left(F_{1,13}=11.52, P=0.004\right)$ and $\mathrm{WT}\left(F_{1,10}=5.54\right.$, $P=0.05$ ) strains, respectively (Figure 4A). For perennial ryegrass, the effects of $\mathrm{Si}$ on endophyte mycelial mass were nonsignificant for all endophyte strains tested (AR1: $F_{1,14}=0.06$, $P=0.80$, AR37: $F_{1,15}=0.08, P=0.77, \mathrm{WT}: F_{1,13}=0.32$, $P=0.56)($ Figure 4B).

\section{DISCUSSION}

In this study, we provide evidence that some Epichloë endophyte strains increased Si concentrations in the foliage of the two most common pasture grasses. Further we show that, whenever endophyte effects on foliar $\mathrm{Si}$ concentration were observed, the magnitude of this increase is positively associated with the amount of Epichloë mycelia in the host plant, and is independent of endophyte stimulation of plant growth. Moreover, using a hydroponic approach, which allows total Si exclusion (all soils contain at least some silicon), we provide novel evidence that Si-supply increases endophyte colonization in tall fescue.

While interactions varied depending on species and endophytic strain in perennial rygrass, reflecting some diversity and complexity in the relationship, for tall fescue, these results provide clear evidence of a reciprocally beneficial interaction between Epichloë-endophytes and Si. The novelty of these findings means that we have limited information about the possible mechanisms. Nonetheless, relevant studies suggest several mechanistic possibilities which we summarize below. While speculative, this provides a basis for future hypothesisdriven experiments including those conducted under more realistic field conditions.

\section{Foliar Si Concentration Increased With Some Endophyte Strains}

Endophyte presence in tall fescue, and particularly the AR37 strain in perennial ryegrass, increased Si concentrations in foliar tissue of their host by more than 30\%. This supports the only existing evidence for such effects, based on field data, by Huitu et al. (2014). Huitu et al. (2014) reported higher foliar Si concentrations in endophyte-colonized meadow fescue (Schedonorus pratensis) field plots compared to endophytefree plots. While providing original evidence of a relationship between Epichloë and Si, Huitu et al. (2014) could not determine whether increases in foliar $\mathrm{Si}$ arose indirectly through endophyte induced changes in plant traits (e.g., increased root mass). Moreover, as a field soil-based study, Si supply could not be controlled, so it was unclear whether $\mathrm{Si}$ affected endophyte colonization. Accurate quantification of plant growth and full control of Si-supply, using the current 
hydroponic approach, allowed these questions to be addressed in the present study.

In this study, Epichloë-mediated increases in $\mathrm{Si}$ were independent of responses in root growth and positively correlated with endophyte colonization, supporting evidence for an intrinsic endophyte effect. One possibility is that symbionts may increase plant transpiration rates resulting in higher passive uptake of Si (Frew et al., 2017; Dastogeer, 2018). For instance, arbuscular mycorrhizae (AM) fungi (Frew et al., 2017), nitrogen fixing bacteria (Hartley and Gange, 2009) and Epichloë endophytes (Llorens et al., 2019) have all been reported to increase plant growth and modify photosynthetic processes through increased stomatal conductance (Malinowski and Belesky, 2000). In line with this, symbionts might also directly affect number and activity of plant aquaporins (water channels that facilitate transport of water between cells) which could promote active Si uptake. For instance, expression of transporter genes in hosts associated with nickel accumulation can be altered by Epichloë (Mirzahossini et al., 2015). Similarly, observed increases in Si could possibly be related to symbionts having aquaporins that operate similarly to those taking-up $\mathrm{Si}$ in plant roots (Frew et al., 2017). Interestingly, when elemental composition of AMfungi spores and extraradical mycelia was investigated, AMfungi displayed selective uptake of various elements, including Si (Hammer et al., 2011). Unfortunately, to our knowledge, the elemental composition of Epichloë-structures has not been investigated so far.
Another putative mechanism could be through endophytemediated alteration of host endogenous defense, or defensepriming (Bastias et al., 2017). Essentially, to maintain functional symbiosis, symbionts increase endogenous levels of the defense hormone jasmonic acid (JA) in their host plant (MartinezMedina et al., 2016). This induction has been reported for obligate symbionts including AM-fungi (Jung et al., 2012), rhizobial bacteria (Dean et al., 2014), as well as, Epichloë endophytes (Bastias et al., 2017). Triggering the JA-pathway, either using chemical stimulation (methyl-jasmonate) or authentic herbivory, has been shown to promote Si-uptake (Ye et al., 2013; Kim et al., 2014; Hall et al., 2019, 2020). Consequently, the resulting spike in JA mediated by Epichloë endophyte symbiosis establishment, may lead to enhanced Si-uptake. However, JA-mediated increases in $\mathrm{Si}$, while significant, have been shown to be relatively small, e.g., 12 and $10 \%$ as reported in Hall et al. (2020, 2019, respectively), compared to $>30 \%$ increased $\mathrm{Si}$ concentration found in this study. This suggests that the stimulation of JA pathway alone is unlikely to be the sole mechanism for increased foliar Si observed in endophyte-symbiotic plants.

Moreover, morphological changes in hosts as a result of endophyte infection have resulted in, for instance, greater number of vascular bundles in perennial ryegrass (Franco et al., 2020). In line with this, Si has been reported in high concentrations both in the vascular bundles of perennial ryegrass (Dinsdale et al., 1979) and in tall fescue (Vandegeer et al., 2020). Thus, indirect morphological changes in hosts as a result of

TABLE 1 | Results from multiple comparison tests (Tukey-adjusted $P$-values) for changes in plant traits as affected by Si and Epichloë endophytes for tall grass fescue and perennial ryegrass.

\begin{tabular}{|c|c|c|c|c|c|c|c|c|}
\hline \multirow[b]{2}{*}{ Grass species } & \multirow[b]{2}{*}{ Factors } & \multirow[b]{2}{*}{$d f$} & \multicolumn{2}{|c|}{ Shoot dry mass } & \multicolumn{2}{|c|}{ Root dry mass } & \multicolumn{2}{|c|}{ Total dry mass } \\
\hline & & & $\boldsymbol{F}$ & $P$ & $\boldsymbol{F}$ & $P$ & $\boldsymbol{F}$ & $P$ \\
\hline \multirow[t]{3}{*}{ Tall fescue } & $\mathrm{Si}$ & 1,90 & 3.02 & 0.085 & 5.14 & 0.026 & 3.39 & 0.051 \\
\hline & Endophyte & 2,90 & 1.61 & 0.204 & 3.93 & 0.023 & 2.06 & 0.133 \\
\hline & $\mathrm{Si} \times$ Endophyte & 2,90 & 2.92 & 0.058 & 0.36 & 0.069 & 2.55 & 0.083 \\
\hline \multirow[t]{3}{*}{ Perennial ryegrass } & $\mathrm{Si}$ & 1,62 & 0.03 & 0.871 & 0.26 & 0.611 & 0.001 & 0.984 \\
\hline & Endophyte & 3,62 & 2.25 & 0.090 & 3.25 & 0.027 & 2.823 & 0.045 \\
\hline & Si $\times$ Endophyte & 3,62 & 2.33 & 0.082 & 0.29 & 0.834 & 1.782 & 0.159 \\
\hline
\end{tabular}

Models with significant $(P<0.05)$ main effects and/or interactions are noted in bold.

TABLE 2 | Results from the multiple comparison tests (Tukey-adjusted P-values) for changes in plant traits as affected by Si on individual Epichloë endophyte strain for fescue and ryegrass, respectively.

\begin{tabular}{|c|c|c|c|c|c|c|c|c|c|}
\hline \multirow[b]{2}{*}{ Grass species } & \multirow[b]{2}{*}{ Strain } & \multirow[b]{2}{*}{ Factor } & \multirow[b]{2}{*}{$d f$} & \multicolumn{2}{|c|}{ Shoot dry mass } & \multicolumn{2}{|c|}{ Root dry mass } & \multicolumn{2}{|c|}{ Total dry mass } \\
\hline & & & & $\boldsymbol{F}$ & $P$ & $\boldsymbol{F}$ & $P$ & $\boldsymbol{F}$ & $P$ \\
\hline \multirow[t]{3}{*}{ Tall fescue } & Nil & $\mathrm{Si}$ & 1,41 & 0.256 & 0.615 & 0.81 & 0.371 & 0.06 & 0.117 \\
\hline & AR584 & & 1,37 & 8.44 & 0.006 & 4.33 & 0.044 & 8.81 & 0.005 \\
\hline & WT & & 1,12 & 0.66 & 0.430 & 0.81 & 0.386 & 0.74 & 0.406 \\
\hline \multirow[t]{4}{*}{ Perennial ryegrass } & Nil & $\mathrm{Si}$ & 1,16 & 3.75 & 0.071 & 0.14 & 0.070 & 2.74 & 0.117 \\
\hline & AR1 & & 1,14 & 1.53 & 0.230 & 0.13 & 0.716 & 1.14 & 0.304 \\
\hline & AR37 & & 1,15 & 1.10 & 0.310 & 0.01 & 0.998 & 1.00 & 0.410 \\
\hline & WT & & 1,17 & 0.91 & 0.353 & 1.52 & 0.234 & 1.24 & 0.280 \\
\hline
\end{tabular}

Models with significant main effects $(P<0.05)$ are noted in bold. 


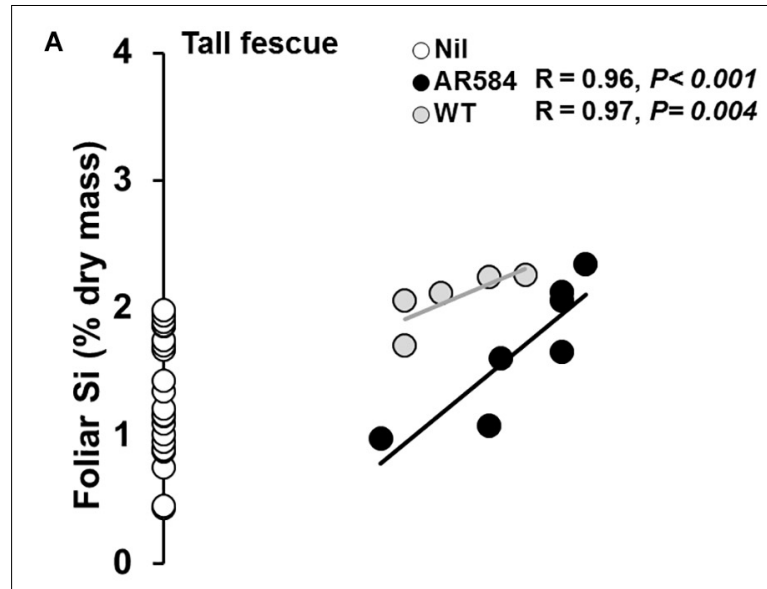

B 47 Perennial ryegrass

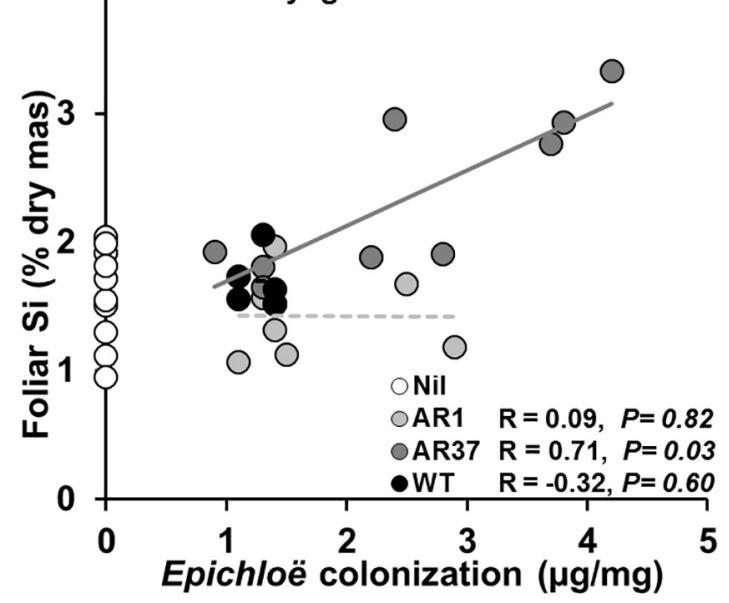

FIGURE 3 | Relationships between Epichloë endophyte colonization and foliar Si concentration in (A) tall fescue and (B) perennial ryegrass with (filled circles) and without (Nil, white circles) endophytes growing hydroponically in the presence of silicon (Si). Lines represent linear regression through data points for each endophyte strain tested. Significant and non-significant relationships represented as solid or dashed lines, respectively. White circles represent Si concentrations from control plants (Nil) confirming lack of endophyte infection and displaying variability of $\mathrm{Si}$ in foliar tissue.

endophyte infection might further increase $\mathrm{Si}$ in host tissues. Further, the amount of Si in grass leaves is known to differ greatly between grass species (Massey et al., 2007), including fescue (Buckner et al., 1967) and perennial ryegrass (Buckner et al., 1967; Moore, 1984). And particularly for tall fescue the amount of Si in grass leaves also varies between varieties, with harsh varieties having higher Si content and more spines on their leaf surface than soft varieties (Hartley et al., 2015). However, for fescue and ryegrass comparable amount of Si concentrations were found for Festuca ovina and Lolium perenne in both controlled (Massey and Hartley, 2009) and field conditions (Massey and Hartley, 2006), and has been directly linked with increasing leaf abrasiveness, thus reduced herbivory (Massey and Hartley, 2006; Massey et al., 2006, 2007). Thus, morphological changes in hosts by both endophyte and Si deposition might be strain and variety specific, highlighting the complexity of these interactions even further.
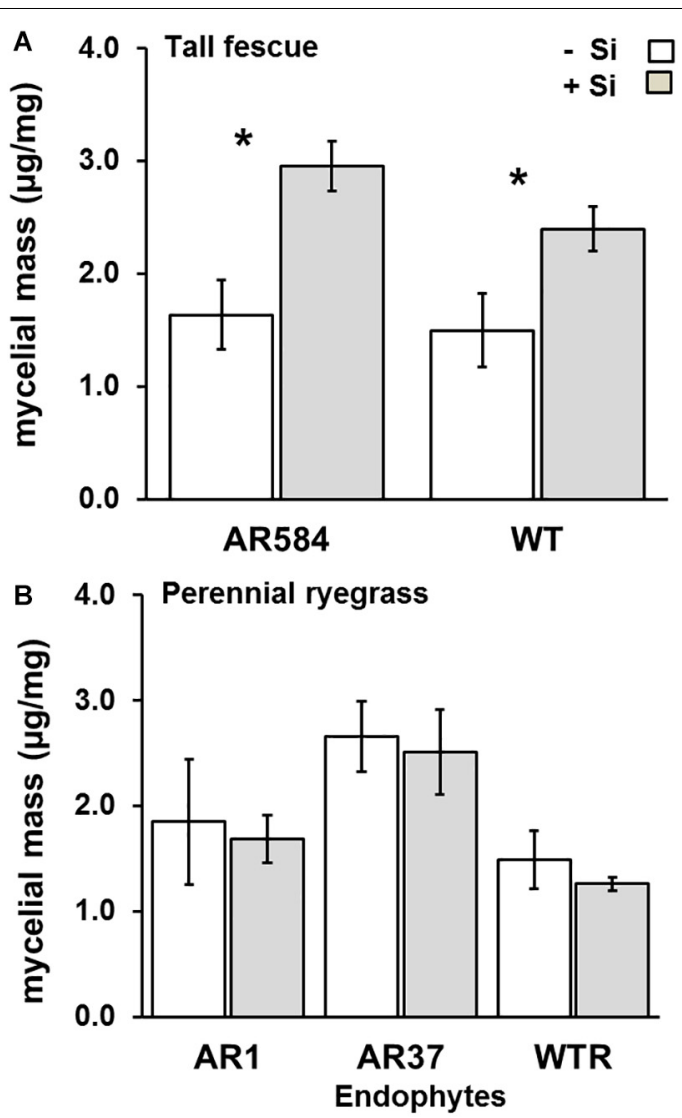

FIGURE 4 | Variation in Epichloë endophyte colonization for (A) tall fescue and (B) perennial ryegrass with colonized different Epichloë endophyte strains growing hydroponically in the absence $(-\mathrm{Si})$ or presence $(+\mathrm{Si})$ of silicon (Si). Mean values \pm standard error shown with $N$ indicated within each bar. $N$ is unbalanced due insufficient material for ELISA (see Supplementary Table S2). Asterisks indicate significant differences $(P<0.05)$ within each endophyte strains.

\section{Si Supply Increases Endophyte Colonization in Tall Fescue}

Si supply did not reduce endophyte colonization in tall fescue nor in perennial ryegrass. This suggests that endophyte development in the apoplast of leaves is not hindered by Si deposition. Instead, endophyte colonization in tall fescue was actually increased by $\mathrm{Si}$ supply. The reasons for this remain speculative, but the natural evolution of a positive/neutral interaction is not unlikely, since grasses have a long evolutionary history with both endophytes (Young et al., 2014) and Si (Cooke and Leishman, 2012).

$\mathrm{Si}$ incorporation into cell walls is known to alter its structure (Kumar et al., 2017), and negative correlations between Si, cellulose and lignin have been reported (Klotzbücher et al., 2018). Likewise, Epichlö̈ endophytes have been shown to decrease concentrations of lignin in perennial ryegrass regardless of plant genotype, and in contrast, showed no effect for tall fescue (Soto-Barajas et al., 2016). Epichloë-effects on host lignin are related to intracellular hyphae obtaining a supplementary source of carbon through hydrolysis of cell wall 
components (carbohydrates) (Rasmussen et al., 2012). Thus, if Si-supplemented plants have reduced lignin, this might affect perennial ryegrass endophyte more so than tall fescue. Thus, instead of interfering with endophyte colonization, Si deposition might in fact create additional niches for Epichlö mycelium (Christensen et al., 2008).

Further, Si accumulation in cell walls in lieu of carbon-rich structural constituents may also make more carbon available for metabolic processes (Cooke and Leishman, 2011), which could be another mechanism by which Si supply increased endophyte colonization in tall fescue. Likewise, since the endophytic fungal partner benefits from the symbiosis withdrawing assimilated photosynthetic carbon, the greater availability of carbon might strengthen the mutualism between Epichloë and its host grass (Rozpądek et al., 2015). Lastly, higher mycelial mass was correlated with increased production of loline-protective alkaloids in Schedonorus pratensis (Cagnano et al., 2020). It is therefore also possible that Si-supply might increase endophyte produced alkaloids in tall fescue, at least, but this remains to be investigated.

\section{CONCLUSION}

There is increasing dependency on grass monocultures (e.g., tall fescue) due to reduced natural grasslands suitable for forage; therefore sustainable strategies such as use of novel endophytes or $\mathrm{Si}$ supplementation to provide better tolerance to biotic stressors are required. Our results provide novel evidence that some Epichloë grass associations increase foliar Si concentrations in both tall fescue and perennial ryegrass, that Si supply can increase Epichloë colonization, and that these effects depend on the specific host species-endophyte strain association considered.

These reciprocal benefits of Epichloë endophytes and $\mathrm{Si}$ accumulation in tall fescue were observed in both WT (mammalian-toxic) and, more importantly, for the animal-safe (novel) AR584 Epichloë strains. Naturally, this needs to occur without major effects on digestibility for livestock, which needs to be further explored. While Si has been reported to cause small reductions in digestible organic matter (Van Soest and Jones, 1968; O'Reagain and Mentis, 1989), it's considered that many ruminants are able to cope with increased $\mathrm{Si}$ in forage crops (Jones and Handreck, 1965; Melzer et al., 2010; Vandevenne et al., 2013). Consequently, the potential for greater resilience to stress by combining endophyte and $\mathrm{Si}$ is clear, particularly for tall fescue.

Moreover, tall fescue-endophyte associations seem to increase resistance to stresses more so than those perennial ryegrassendophyte associations (Young et al., 2013). Both endophytes and

\section{REFERENCES}

Bastias, S., Martínez-Ghersa, M., Ballaré, C., and Gundel, P. (2017). Epichloë fungal endophytes and plant defenses: not just alkaloids. Trends Plant Sci. 22, 939-948. doi: 10.1016/j.tplants.2017.08.005

Buckner, R. C., Todd, J. R., Burrus, P. B., and Barnes, R. F. (1967). Chemical composition, palatability, and digestibility of ryegrass-tall fescue Hybrids,
Si accumulation can individually suppress pests but the current findings, albeit from highly controlled conditions, suggest there is at least the potential for them to work in combination. Future studies should explore these interactions with the inclusion of herbivores and in natural field conditions to determine whether this potential can be realized.

\section{DATA AVAILABILITY STATEMENT}

The original contributions presented in the study are included in the article/Supplementary Material, further inquiries can be directed to the corresponding author.

\section{AUTHOR CONTRIBUTIONS}

$\mathrm{XC}-\mathrm{S}$, JP, and SJ planned and designed the research. XC$S$ conducted the experimental work, collected the data, and analyzed the data with input from JP and SJ. XC-S led the writing of the manuscript with significant input from SJ, JP, FL, AP, and $\mathrm{SH}$. All authors contributed to the article and approved the submitted version.

\section{FUNDING}

This research was supported by the Australian Research Council Discovery (grant no. DP170102278).

\section{ACKNOWLEDGMENTS}

We acknowledge Dr. Jan Sprosen and Dr. Anouck de Bonth for assistance on immunoblotting and ELISAs. The Margot Forde Germplasm Centre (Palmerston North, New Zealand) for providing the grass seeds and Juan Raul Bentancur for technical assistance. Special thanks go to Dr. Silvina Stewart, Dr. Rebecca K. Vandegeer, Dr. Casey Hall, and Rocky Putra for feedback on the manuscript.

\section{SUPPLEMENTARY MATERIAL}

The Supplementary Material for this article can be found online at: https://www.frontiersin.org/articles/10.3389/fpls.2020. 593198/full\#supplementary-material

'Kenwell', and 'Kentucky 31' tall fescue varieties. Agron. J. 59, 345-349. doi: 10.2134/agronj1967.00021962005900040018x

Cagnano, G., Lenk, I., Roulund, N., Jensen, C. S., Cox, M. P., and Asp, T. (2020). Mycelial biomass and concentration of loline alkaloids driven by complex population structure in Epichloë uncinata and meadow fescue (Schedonorus pratensis). Mycologia 112, 474-490. doi: 10.1080/00275514.2020. 1746607 
Cheplick, G. P. (2007). Costs of fungal endophyte infection in Lolium perenne genotypes from Eurasia and North Africa under extreme resource limitation. Environ. Exp. Bot. 60, 202-210. doi: 10.1016/j.envexpbot.2006.10.001

Cheplick, G. P., Clay, K., and Marks, S. (1989). Interactions between infection by endophytic fungi and nutrient limitation in the grasses Lolium perenne and Festuca arundinacea. New Phytol. 111, 89-97. doi: 10.1111/j.1469-8137.1989. tb04222.x

Cheplick, G. P., and Faeth, S. H. (2009). Ecology and evolution of the grassendophyte symbiosis. Oxford: Oxford University Press, 1-253.

Christensen, M. J., Bennett, R. J., Ansari, H. A., Koga, H., Johnson, R. D., Bryan, G. T., et al. (2008). Epichloë endophytes grow by intercalary hyphal extension in elongating grass leaves. Fungal Genet. Biol. 45, 84-93. doi: 10.1016/j.fgb.2007. 07.013

Cooke, J., and Leishman, M. (2011). Is plant ecology more siliceous than we realise? Trends Plant Sci. 16, 61-68. doi: 10.1016/j.tplants.2010.10.003

Cooke, J., and Leishman, M. (2012). Tradeoffs between foliar silicon and carbonbased defences: evidence from vegetation communities of contrasting soil types. Oikos 121, 2052-2060. doi: 10.1111/j.1600-0706.2012.20057.x

Coskun, D., Deshmukh, R., Sonah, H., Menzies, J. G., Reynolds, O., Ma, J. F., et al. (2019). The controversies of silicon's role in plant biology. New Phytol. 221, 67-85. doi: $10.1111 /$ nph.15343

Dastogeer, K. M. G. (2018). Influence of fungal endophytes on plant physiology is more pronounced under stress than well-watered conditions: a meta-analysis. Planta 248, 1403-1416. doi: 10.1007/s00425-018-2982-y

Dean, J. M., Mescher, M. C., and De Moraes, C. M. (2014). Plant dependence on rhizobia for nitrogen influences induced plant defenses and herbivore performance. Int. J. Mol. Sci. 15, 1466-1480. doi: 10.3390/ijms15011466

di Menna, M. E., Finch, S. C., Popay, A. J., and Smith, B. L. (2012). A review of the Neotyphodium lolii / Lolium perenne symbiosis and its associated effects on animal and plant health, with particular emphasis on ryegrass staggers. N. Z. Vet. J. 60, 315-328. doi: 10.1080/00480169.2012.697429

Dinsdale, D., Gordon, A. H., and George, S. (1979). Silica in the mesophyll cell walls of italian rye grass (Lolium multiflorum Lam. cv. RvP). Ann. Bot. 44, 73-77. doi: 10.1093/oxfordjournals.aob.a085708

Easton, H. S., Latch, G. C. M., Tapper, B. A., and Ball, O. J. P. (2002). Ryegrass host genetic control of concentrations of endophyte-derived alkaloids. Crop Sci. 42, 51-57. doi: 10.2135/cropsci2002.0051

Eneji, A. E., Inanaga, S., Muranaka, S., Li, J., Hattori, T., An, P., et al. (2008). Growth and nutrient use in four grasses under drought stress as mediated by silicon fertilizers. J. Plant Nutr. 31, 355-365. doi: 10.1080/01904160801894913

Epstein, E. (1994). The anomaly of silicon in plant biology. Proc. Natl. Acad. Sci. U.S.A. 91, 11-17. doi: 10.1073/pnas.91.1.11

Franco, M. F., Colabelli, M. N., Echeverría, M de M, and Ispizúa, V. N. (2020). Epichloe endophyte modifies the foliar anatomy of Lolium multiflorum Lam. Symbiosis 81, 313-319. doi: 10.1007/s13199-020-00702-y

Frew, A., Powell, J. R., Allsopp, P. G., Sallam, N., and Johnson, S. N. (2017). Arbuscular mycorrhizal fungi promote silicon accumulation in plant roots, reducing the impacts of root herbivory. Plant Soil 419, 423-433. doi: 10.1007/ s11104-017-3357-z

Frew, A., Weston, L. A., Reynolds, O. L., and Gurr, G. M. (2018). The role of silicon in plant biology: a paradigm shift in research approach. Ann. Bot. 121, 1265-1273. doi: 10.1093/aob/mcy009

García Parisi, P. A., Lattanzi, F. A., Grimoldi, A. A., and Omacini, M. (2015). Multi-symbiotic systems: functional implications of the coexistence of grassendophyte and legume-rhizobia symbioses. Oikos 124, 553-560. doi: 10.1111/ oik.01540

Gundel, P. E., Pérez, L. I., Helander, M., and Saikkonen, K. (2013). Symbiotically modified organisms: nontoxic fungal endophytes in grasses. Trends Plant Sci. 18, 420-427. doi: 10.1016/j.tplants.2013.03.003

Hahn, H., Huth, W., Schöberlein, W., and Diepenbrock, W. (2003). Detection of endophytic fungi in Festuca spp. by means of tissue print immunoassay. Plant Breed. 122, 217-222. doi: 10.1046/j.1439-0523.2003.00855.x

Hall, C. R., Mikhael, M., Hartley, S. E., and Johnson, S. N. (2020). Elevated atmospheric $\mathrm{CO}_{2}$ suppresses jasmonate and silicon-based defences without affecting herbivores. Funct. Ecol. 34, 993-1003. doi: 10.1111/1365-2435.13549

Hall, C. R., Waterman, J. M., Vandegeer, R. K., Hartley, S. E., and Johnson, S. N. (2019). The role of silicon in antiherbivore phytohormonal signalling. Front. Plant Sci. 10:1132. doi: 10.3389/fpls.2019.01132
Hammer, E. C., Nasr, H., Pallon, J., Olsson, P. A., and Wallander, H. (2011). Elemental composition of arbuscular mycorrhizal fungi at high salinity. Mycorrhiza 21, 117-129. doi: 10.1007/s00572-010-0316-4

Hartley, S. E., Fitt, R. N., McLarnon, E. L., and Wade, R. N. (2015). Defending the leaf surface: intra- and inter-specific differences in silicon deposition in grasses in response to damage and silicon supply. Front. Plant Sci. 6:35. doi: 10.3389/fpls.2015.00035

Hartley, S. E., and Gange, A. C. (2009). Impacts of plant symbiotic fungi on insect herbivores: mutualism in a multitrophic context. Annu. Rev. Entomol. 54, 323-342. doi: 10.1146/annurev.ento.54.110807.090614

Heineck, G. C., Qiu, Y., Ehlke, N. J., and Watkins, E. (2020). The fungal endophyte Epichloe festucae var. lolii plays a limited role in mediating crown rust severity in perennial ryegrass. Crop Sci. 60, 1090-1104. doi: 10.1002/csc2.20095

Hiltpold, I., Demarta, L., Johnson, S. N., Moore, B. D., Power, S. A., and Mitchell, C. (2016). "Silicon and other essential element composition in roots using X-ray fluorescence spectroscopy: a high throughput approach. Invertebrate Ecology of Australasian Grasslands," in Proceedings of the Ninth ACGIE (Hawkesbury, NSW), 191-196.

Huitu, O., Forbes, K. M., Helander, M., Julkunen-Tiitto, R., Lambin, X., Saikkonen, K., et al. (2014). Silicon, endophytes and secondary metabolites as grass defenses against mammalian herbivores. Front. Plant Sci. 5:478. doi: 10.3389/fpls.2014. 00478

Hume, D. E., Card, S. D., and Rolston, M. P. (2013). "Effects of storage conditions on endophyte and seed viability in pasture grasses," in Proceedings of the 22nd International Grassland Congress (Sydney), 405-408.

Johnson, S. N., Benefer, C. M., Frew, A., Griffiths, B. S., Hartley, S. E., Karley, A. J., et al. (2016). New frontiers in belowground ecology for plant protection from root-feeding insects. Appl. Soil. Ecol. 108, 96-107. doi: 10.1016/j.apsoil.2016.07. 017

Jones, L. H. P., and Handreck, K. A. (1965). The relation between the silica content of the diet and the excretion of silica by sheep. J. Agric. Sci. 65, 129-134. doi: $10.1017 / \mathrm{s} 0021859600085439$

Jung, H., Yan, J., Zhai, Z., and Vatamaniuk, O. K. (2015). “Gene functional analysis using protoplast transient assays," in Plant Functional Genomics: Methods and Protocols, 2th Edn, ed. E. Grotewold (Totowa, NJ: Humana Press), 1-526.

Jung, S. C., Martinez-Medina, A., Lopez-Raez, J. A., and Pozo, M. J. (2012). Mycorrhiza-induced resistance and priming of plant defenses. J. Chem. Ecol. 38, 651-664. doi: 10.1007/s10886-012-0134-6

Kauppinen, M., Saikkonen, K., Helander, M., Pirttilä, A. M., and Wäli, P. R. (2016). Epichloë grass endophytes in sustainable agriculture. Nat. Plants 2:15224.

Kaur, J., Ekanayake, P. N., Tian, P., van Zijll de Jong, E., Dobrowolski, M. P., Rochfort, S. J., et al. (2015). Discovery and characterisation of novel asexual Epichloë endophytes from perennial ryegrass (Lolium perenne L.). Crop Pasture Sci. 66, 1058-1070. doi: 10.1071/cp14332

Kim, Y. H., Khan, A. L., Waqas, M., Jeong, H. J., Kim, D. H., Shin, J. S., et al. (2014). Regulation of jasmonic acid biosynthesis by silicon application during physical injury to Oryza sativa L. J. Plant Res. 127, 525-532. doi: 10.1007/s10265-0140641-3

Klotzbücher, T., Klotzbücher, A., Kaiser, K., Vetterlein, D., Jahn, R., and Mikutta, R. (2018). Variable silicon accumulation in plants affects terrestrial carbon cycling by controlling lignin synthesis. Glob. Chang. Biol. 24, e183-e189.

Krings, M., Taylor, T. N., Hass, H., Kerp, H., Dotzler, N., and Hermsen, E. J. (2007). Fungal endophytes in a 400-million-yr-old land plant: infection pathways, spatial distribution, and host responses. New Phytol. 174, 648-657. doi: 10. $1111 /$ j.1469-8137.2007.02008.x

Kuldau, G., and Bacon, C. (2008). Clavicipitaceous endophytes: their ability to enhance resistance of grasses to multiple stresses. Biol. Control 46, 57-71. doi: 10.1016/j.biocontrol.2008.01.023

Kumar, S., Soukup, M., and Elbaum, R. (2017). Silicification in grasses: variation between different cell types. Front. Plant Sci. 8:438. doi: 10.3389/fpls.2017. 00438

Latch, G. C. M., and Christensen, M. J. (1985). Artificial infection of grasses with endophytes. Ann. Appl. Biol. 107, 17-24. doi: 10.1111/j.1744-7348.1985. tb01543.x

Leuchtmann, A. (1992). Systematics, distribution, and host specificity of grass endophytes. Nat. Toxins 1, 150-162. doi: 10.1002/nt.2620010303

Llorens, E., Sharon, O., Camañes, G., García-Agustín, P., and Sharon, A. (2019). Endophytes from wild cereals protect wheat plants from drought by alteration 
of physiological responses of the plants to water stress. Environ. Microbiol. 21, 3299-3312. doi: 10.1111/1462-2920.14530

Ma, J. F., and Yamaji, N. (2006). Silicon uptake and accumulation in higher plants. Trends Plant Sci. 11, 392-397. doi: 10.1016/j.tplants.2006.06.007

Ma, J. F., and Yamaji, N. (2015). A cooperative system of silicon transport in plants. Trends Plant Sci. 20, 435-442. doi: 10.1016/j.tplants.2015.04.007

Malinowski, D. P., Alloush, G. A., and Belesky, D. P. (1998). Evidence for chemical changes on the root surface of fall fescue in response to infection with the fungal endophyte Neotyphodium coenophialum. Plant Soil 205, 1-12.

Malinowski, D. P., and Belesky, D. P. (2000). Adaptations of endophyte-infected cool-season grasses to environmental stresses: mechanisms of drought and mineral stress tolerance. Crop Sci. 40, 923-940. doi: 10.2135/cropsci2000. $404923 x$

Malinowski, D. P., Zuo, H., Belesky, D. P., and Alloush, G. A. (2004). Evidence for copper binding by extracellular root exudates of tall fescue but not perennial ryegrass infected with Neotyphodium spp. endophytes. Plant Soil 267, 1-12. doi: 10.1007/s11104-005-2575-y

Martinez-Medina, A., Flors, V., Heil, M., Mauch-Mani, B., Pieterse, C. M. J., Pozo, M. J., et al. (2016). Recognizing plant defense priming. Trends Plant Sci. 21, 818-822. doi: 10.1016/j.tplants.2016.07.009

Massey, F., Ennos, A., and Hartley, S. (2006). Silica in grasses as a defence against insect herbivores: contrasting effects on folivores and a phloem feeder. J. Anim. Ecol. 75, 595-603. doi: 10.1111/j.1365-2656.2006.01082.x

Massey, F., and Hartley, S. (2009). Physical defences wear you down : progressive and irreversible impacts of silica on insect herbivores. J. Anim. Ecol. 78, 281-291. doi: 10.1111/j.1365-2656.2008.01472.x

Massey, F. P., Ennos, A. R., and Hartley, S. E. (2007). Grasses and the resource availability hypothesis: the importance of silica-based defences. J. Ecol. 95, 414-424. doi: 10.1111/j.1365-2745.2007.01223.x

Massey, F. P., and Hartley, S. E. (2006). Experimental demonstration of the antiherbivore effects of silica in grasses: impacts on foliage digestibility and vole growth rates. Proc. R. Soc. B Biol. Sci. 273, 2299-2304. doi: 10.1098/rspb.2006. 3586

Melzer, S. E., Knapp, A. K., Kirkman, K. P., Smith, M. D., Blair, J. M., and Kelly, E. F. (2010). Fire and grazing impacts on silica production and storage in grass dominated ecosystems. Biogeochemistry 97, 263-278. doi: 10.1007/s10533-0099371-3

Miao, B. H., Han, X. G., and Zhang, W. H. (2010). The ameliorative effect of silicon on soybean seedlings grown in potassium-deficient medium. Ann. Bot. 105, 967-973. doi: 10.1093/aob/mcq063

Miles, C. O., Di Menna, M. E., Jacobs, S. W. L., Garthwaite, I., Lane, G. A., Prestidge, R. A., et al. (1998). Endophytic fungi in indigenous Australasian grasses associated with toxicity to livestock. Appl. Environ. Microbiol. 64, 601-606. doi: 10.1128/aem.64.2.601-606.1998

Mirzahossini, Z., Shabani, L., Sabzalian, M. R., and Sharifi-Tehrani, M. (2015). $\mathrm{ABC}$ transporter and metallothionein expression affected by NI and Epichloe endophyte Infection in tall fescue. Ecotoxicol. Environ. Saf. 120, 13-19. doi: 10.1016/j.ecoenv.2015.05.025

Moore, D. (1984). The role of silica in protecting Italian ryegrass (Lolium multiflorum) from attack by dipterous stem boring larvae (Oscinella frit and other related species). Ann. Appl. Biol. 104, 161-166. doi: 10.1111/j.1744-7348. 1984.tb05598.x

Munday, J. S., Finch, S. C., Vlaming, J. B., Sutherland, B. L., and Fletcher, L. R. (2017). Pathological changes seen in horses in New Zealand grazing Mediterranean tall fescue (Lolium arundinaceum) infected with selected endophytes (Epichloë coenophiala) causing equine fescue oedema. $N$. Z. Vet. J. 65, 147-151. doi: 10.1080/00480169.2016.1248516

Niones, J. T., and Takemoto, D. (2014). An isolate of Epichloë festucae, an endophytic fungus of temperate grasses, has growth inhibitory activity against selected grass pathogens. J. Gen. Plant Pathol. 80, 337-347. doi: 10.1007/ s10327-014-0521-7

Novas, M. V., Iannone, L. J., Godeas, A. M., and Scervino, J. M. (2011). Evidence for leaf endophyte regulation of root symbionts: effect of Neotyphodium endophytes on the pre-infective state of mycorrhizal fungi. Symbiosis 55, 19-28. doi: 10.1007/s13199-011-0140-4

O’Reagain, P. J., and Mentis, M. T. (1989). Leaf silicification in grasses-a review. J. Grassl. Soc. South Africa 6, 37-43. doi: 10.1080/02566702.1989.9648158
Perez, L. I., Gundel, P. E., Marrero, H. J., Arzac, A. G., and Omacini, M. (2017). Symbiosis with systemic fungal endophytes promotes host escape from vector-borne disease. Oecologia 184, 237-245. doi: 10.1007/s00442-0173850-3

R Core Team (2020). R: A Language and Environment for Statistical Computing. Vienna: R Foundation for Statistical Computing. Available online at: https: //www.R-project.org/

Rasmussen, S., Liu, Q., Parsons, A., Xue, H., Sinclair, B., and Newman, J. (2012). Grass-endophyte interactions : a note on the role of monosaccharide transport in the Neotyphodium lolii-Lolium perenne symbiosis. New Phytol. 196, 7-12. doi: $10.1111 / j .1469-8137.2012 .04250 . x$

Rasoolizadeh, A., Labbé, C., Sonah, H., Deshmukh, R. K., Belzile, F., Menzies, J. G., et al. (2018). Silicon protects soybean plants against Phytophthora sojae by interfering with effector-receptor expression. BMC Plant Biol. 18:97. doi: 10.1186/s12870-018-1312-7

Raven, J. A. (1983). The transport and function of silicon in plants. Biol. Rev. 58, 179-207. doi: 10.1111/j.1469-185x.1983.tb00385.x

Reidinger, S., Ramsey, M. H., and Hartley, S. H. (2012). Rapid and accurate analyses of silicon and phosphorus in plants using a portable X-ray fluorescence spectrometers. New Phytol. 195, 699-706. doi: 10.1111/j.1469-8137.2012. 04179.x

Ren, A. Z., Gao, Y. B., and Zhou, F. (2007). Response of Neotyphodium lolii-infected perennial ryegrass to phosphorus deficiency. Plant Soil Environ. 53, 113-119. doi: 10.17221/2225-pse

Reynolds, O. L., Padula, M. P., Zeng, R., and Gurr, G. M. (2016). Silicon: potential to promote direct and indirect effects on plant defense against arthropod pests in agriculture. Front. Plant Sci. 7:744. doi: 10.3389/fpls.2016. 00744

Rho, H., Hsieh, M., Kandel, S. L., Cantillo, J., Doty, S. L., and Kim, S.-H. (2018). Do endophytes promote growth of host plants under stress? A Meta-Analysis on plant stress mitigation by endophytes. Microb. Ecol. 75, 407-418. doi: 10.1007/s00248-017-1054-3

Rozpądek, P., Wêżowicz, K., Nosek, M., Ważny, R., Tokarz, K., Lembicz, M., et al. (2015). The fungal endophyte Epichloë typhina improves photosynthesis efficiency of its host orchard grass (Dactylis glomerata). Planta 242, 1025-1035. doi: 10.1007/s00425-015-2337-x

Saikkonen, K., Young, C. A., Helander, M., and Schardl, C. L. (2016). Endophytic Epichloë species and their grass hosts: from evolution to applications. Plant Mol. Biol. 90, 665-675. doi: 10.1007/s11103-015-0399-6

Soto-Barajas, M. C., Zabalgogeazcoa, I., Gómez-Fuertes, J., González-Blanco, V., and Vázquez-de-Aldana, B. R. (2016). Epichloë endophytes affect the nutrient and fiber content of Lolium perenne regardless of plant genotype. Plant Soil 405, 265-277. doi: 10.1007/s11104-015-2617-z

Tripathi, D. K., Singh, S., Singh, V. P., Prasad, S. M., Dubey, N. K., and Chauhan, D. K. (2017). Silicon nanoparticles more effectively alleviated UV-B stress than silicon in wheat (Triticum aestivum) seedlings. Plant Physiol. Biochem. 110, 70-81. doi: 10.1016/j.plaphy.2016.06.026

Van Soest, P. J., and Jones, L. H. P. (1968). Effect of silica in forages upon digestibility. J. Dairy Sci. 51, 1644-1648. doi: 10.3168/jds.s0022-0302(68) 87246-7

Vandegeer, R. K., Zhao, C., Cibils-Stewart, X., Wuhrer, R., Hall, C. R., Hartley, S. E., et al. (2020). Silicon deposition on guard cells increases stomatal sensitivity as mediated by $\mathrm{K}^{+}$efflux and consequently reduces stomatal conductance. Physiol. Plant. doi: $10.1111 / \mathrm{ppl} .13202$

Vandevenne, F. I., Barão, A. L., Schoelynck, J., Smis, A., Ryken, N., Van Damme, S., et al. (2013). Grazers: biocatalysts of terrestrial silica cycling. Proc. R. Soc. B Biol. Sci. 280.

Vivancos, J., Labbé, C., Menzies, J. G., and Bélanger, R. R. (2015). Silicon-mediated resistance of Arabidopsis against powdery mildew involves mechanisms other than the salicylic acid (SA)-dependent defence pathway. Mol. Plant Pathol. 16, 572-582. doi: 10.1111/mpp.12213

Wiewióra, B., Zurek, G., and Zurek, M. (2015). Endophyte-mediated disease resistance in wild populations of perennial ryegrass (Lolium perenne). Fungal Ecol. 15, 1-8. doi: 10.1016/j.funeco.2015. 01.004

Xia, C., Li, N., Zhang, Y., Li, C., Zhang, X., and Nan, Z. (2018). Role of Epichloë endophytes in defense responses of cool-season grasses to 
pathogens: a Review. Plant Dis. 102, 2061-2073. doi: 10.1094/pdis-05-180762-fe

Ye, M., Zeng, R., Cai, K., Long, J., Zhu-Salzman, K., Wang, R., et al. (2013). Priming of jasmonate-mediated antiherbivore defense responses in rice by silicon. Proc. Natl. Acad. Sci. U.S.A. 110, E3631-E3639.

Young, C. A., Charlton, N. D., Takach, J. E., Swoboda, G. A., Trammell, M. A., Huhman, D. V., et al. (2014). Characterization of Epichloë coenophiala within the US: are all tall fescue endophytes created equal? Front. Chem. 2:95. doi: 10.3389/fchem.2014.00095

Young, C. A., Hume, D. E., and McCulley, R. L. (2013). Forages and pastures symposium: fungal endophytes of tall fescue and perennial ryegrass: pasture friend or foe? J. Anim. Sci. 91, 2379-2394. doi: 10.2527/jas.2012-5951

Zhang, J., Sun, W., Ding, Y., Liang, Y., Zhu, J., Chu, G., et al. (2008). Role of silicon in enhancing resistance to freezing stress in two contrasting winter wheat cultivars. Environ. Exp. Bot. 64, 286-294. doi: 10.1016/j.envexpbot.2008. 06.005

Conflict of Interest: The authors declare that the research was conducted in the absence of any commercial or financial relationships that could be construed as a potential conflict of interest.

Copyright (C) 2020 Cibils-Stewart, Powell, Popay, Lattanzi, Hartley and Johnson. This is an open-access article distributed under the terms of the Creative Commons Attribution License (CC BY). The use, distribution or reproduction in other forums is permitted, provided the original author(s) and the copyright owner(s) are credited and that the original publication in this journal is cited, in accordance with accepted academic practice. No use, distribution or reproduction is permitted which does not comply with these terms. 